\title{
Following the Curve?
}

\author{
Mike Kirkby $^{1}$ and Artemi Cerda ${ }^{2}$ \\ ${ }^{1}$ University of Leeds School of Geography \\ ${ }^{2}$ Universitat de Valencia
}

May 11, 2021

\begin{abstract}
Output from a runoff generation models is compared here with information from field measurements, making use of 11 years data from rainfall and runoff events at the Sierra de Enguera Soil Erosion Experimental Station in Eastern Spain.. The model presented simulates overland storm flow on a sloping rough and unvegetated surface, representing an area of 320x320 m. GreenAmpt infiltration constants are randomly assigned to each cell in a 128x128 grid, and rectangular storms applied at a range of total amounts and intensities to simulate runoff at each transect across the area. A simple algebraic expression is developed to estimate total runoff and storage in terms of storm size and duration, and plot length, with parameters that reflect infiltration behaviour, and this expression is compared with the SCS curve number approach. Output of these simulations is compared with measured storm runoff data on bare runoff plots at the Sierra de Enguera experimental Station in SE Spain and gives further support to the proposed expression for storm runoff.
\end{abstract}

Following the Curve?

Mike Kirkby $^{1 *}$, Artemi Cerdà ${ }^{2}$,

${ }^{1}$ School of Geography, University of Leeds, Leeds LS2 9JT, UK m.j.kirkby@leeds.ac.uk

2 Soil Erosion and Degradation Research Group. Department of Geography, Valencia University, Blasco Ibànez, 28, 46010 Valencia, Spain; artemio.cerda@uv.es

* Corresponding author

\section{Abstract}

Output from a runoff generation models is compared here with information from field measurements, making use of 11 years data from rainfall and runoff events at the Sierra de Enguera Soil Erosion Experimental Station in Eastern Spain.. The model presented simulates overland storm flow on a sloping rough and unvegetated surface, representing an area of 320x320 m. Green-Ampt infiltration constants are randomly assigned to each cell in a 128x128 grid, and rectangular storms applied at a range of total amounts and intensities to simulate runoff at each transect across the area. A simple algebraic expression is developed to estimate total runoff and storage in terms of storm size and duration, and plot length, with parameters that reflect infiltration behaviour, and this expression is compared with the SCS curve number approach. Output of these simulations is compared with measured storm runoff data on bare runoff plots at the Sierra de Enguera experimental Station in SE Spain and gives further support to the proposed expression for storm runoff.

Key words: storm runoff, runoff plot, simulation model, SCS curve number

\section{Rationale}

Lateral near-surface flow has been envisaged as generated, either where rainfall intensity exceeds the infiltration capacity of the soil surface (infiltration excess overland flow: Horton, 1931), or where the soil becomes 
saturated so that additional rainfall is diverted laterally (saturation excess overland flow: Dunne and Black, 1970). It is now recognised (Cammeraat, 2002; McDonell, 2003) that rainfall intensity may exceed the capacity of the soil to percolate downwards at either the surface or within the soil (Figure 1), and that significant spatial variations in infiltration rate can lead to a 'fill and spill' pattern of saturated patches which overflow and connect during storms to drive surface and/or subsurface lateral flow. In this paper these spatial patterns are simulated for infiltration excess overland flow with the saturated patches at the surface, but it is recognised that there may be strong similarities between surface and subsurface patterns (McDonnell, 2013).

The SCS Curve number has been the most widely used model to forecast total storm runoff from total storm rainfall and is embedded within a number of other models that are used to forecast erosion and solute behaviour at range of scales. Despite its widespread application, the curve number method has little theoretical underpinning, and is not explicitly related to spatial scale or topography. Various attempts to partially remedy these deficiencies (Porporato et al, 2016, Williams et al, 2012) have been proposed.

Rainstorms are rarely simple in profile or in antecedent conditions, so that any simple rainfall-runoff relationship is likely to show wide variations. The bar for acceptability is therefore low, and the approach is only justifiable if kept simple, facilitating inclusion in other models.

The approach taken here has been applied for conditions of infiltration excess overland flow, although comparisons may be drawn with sub-surface fill-and-spill configurations. Flow patterns and slope-base output from a square sloping plot have been simulated for isolated storms of constant intensity. The plot has a roughened surface and randomly distributed infiltration parameters. During a storm, areas of low infiltration create patches of saturation that generate overland flow which may connect with other saturated patches or reinfiltrate downslope in patches of higher infiltration. Saturated areas close to the slope base provide some outflow, even in brief and/or low intensity storms. In progressively larger storms, overland flow connections with the slope base are established farther and farther up the slope. After rainfall stops, there is no more flow contribution from the top of the slope, but connected flow persists downslope in areas of flow concentration and shapes the recession limb of the outlet hydrograph.

The detailed model that has been used (Kirkby, 2014) generates infiltration excess overland flow on a grid representing either a fractally roughened uniform slope or a more topographically structured surface with distinct valleys. Green Ampt (1911) infiltration parameters are randomly assigned for each cell (nominally of $2.5 \mathrm{~m}$ in the $128 \times 128$ cell grid), with values drawn from a specified distribution based on field measurements in S.E. Spain. Overland flow is routed downslope across the surface, according to a probability distribution of overland flow 'droplets' based on D8 flow directions, a method that has also been applied for saturation excess overland flow (Gao et al 2016,2017). Overland flow is generated in a source cell wherever inflow and rainfall exceed infiltration. 50 instances of this overland flow are treated as droplets, each of which travels towards a neighbouring cell randomly chosen from the probabilities assigned to each downslope direction. The droplet mean velocity is calculated from the local gradient and overland flow depth to determine the probability of stopping, at the end of the time step, in the receiving cell. If not stopping this process is repeated until the droplet comes to rest. This process is repeated for the 50 droplets and their mean is used to define the redistribution of the overland flow generated in the source cell at each time step.

The previous work (Kirkby, 2014) simulated total storm runoff, rat the slope base from simple storms of constant intensity and total storm rainfall $R$, on initially dry surfaces.

The expressions derived are well behaved at extreme values in the following ways.

First $r=0$ when $R=0$. This is a self-evident requirement. Second, there is very low runoff for small storms, for which equation (1) behaves like $r^{\sim} R^{n+1}$. This seems to be a more appropriate response than the sharp lower threshold for runoff in the SCS curve number method, since both model and field data (Cammeraat, 2002) show that, in even small storms, patches of low infiltration near the outlet boundary are able to deliver small amounts of runoff before their flow contribution is absorbed in higher infiltration areas. Thirdly, at high storm amounts, runoff asymptotically approaches rainfall, a behaviour in common with the SCS approach. However, the expression previously proposed seemed to suggest that the volume of infiltrated water stored in 
the soil, together with the volume of water in detention upon the surface decreased as total storm rainfall was increased, appearing to violate the requirements of mass balance, and leading to the alternative formulations proposed here, that differ appreciably in the forecast volume of runoff for the largest storms.

\section{Internal runoff structure}

This paper explores the internal structure and implicit connectivity within the modelled hillslope, in order to further generalise and improve the rainfall-runoff model previously presented and examine its internal structure. The model output that underlies this relationship can be illustrated through examples. The storms have been generated on a roughened surface draped across a uniform slope. Figure 2(a) shows the contours on an example surface used here. Figure 2(b) shows total storm discharge at every point on this surface, after applying a $120 \mathrm{~mm}$ storm at an intensity of $30 \mathrm{~mm}$ per hour. Discharge is in units of $\mathrm{mm} \times$ cell length

. The random convergences are sufficient to create local concentrations of catchment area and discharge towards the base of the slope, with discharge generally increasing with area, both downslope and laterally, in convergent areas.

The relationship between discharge and area is illustrated explicitly in figure 3, for two contrasting storm sizes, and with higher infiltration rates in (b). Values for every cell across the grid are plotted for three crossslope transects near the top, middle and bottom of the slope. The horizontal axis shows the areas drained to each individual cell across the transect, with their average equal to the transect value, $x$. It can be seen that the roughening of the surface produces a wide range of areas within the transect. In each case there are strong overall relationships, and the trend within individual transects differs slightly from the overall trend. It is also clear from the regression lines that discharge increases less than linearly with area, and more strongly so for the smaller storm ad higher infiltration (in figure 3b), so that runoff (discharge per unit area) is decreasing with area drained. In a simulated storm, four stages of response can be distinguished. Figure 4 shows two example hydrographs that illustrate these stages.

1. At the very start of a storm, infiltration capacity is theoretically very large, following the Green- $\mid$ Ampt expression $f=A+B / S(1)$ where $f$ is the instantaneous infiltration rate $\left(\mathrm{mm} . \mathrm{hr}^{-1}\right), S$ is the conceptual near-surface storage ( $\mathrm{mm}$ : initially zero) and $A, B$ are the parameter values that are randomly and independently distributed across grid cells. $A$ is the steady infiltration rate that conceptually leaks from the near-surface store until it is exhausted, and represents the steady final long-term infiltration rate. $B$ controls the initial rapid infiltration onto the near-surface store, $S$. In this first stage, almost all rain infiltrates into the near surface store, and there is only very limited runoff from saturated patches close to the outlet.

2. Quite soon near-surface storage increases, and, in the second stage, infiltration rate is controlled by equation (1) over an increasing proportion of the area. Average detention depths increase but slopebase runoff increases only slowly, since much of the ponded water is not connected to the slope base. In large storms, runoff may reach an almost steady state, in which rainfall intensity is partitioned between infiltration and runoff (figure 4b), whereas in smaller storms (figure 4a) runoff continues to increase.

3. A third stage begins when storm rainfall ends. Existing detention continues to support infiltration, though over a shrinking area. This allows further addition to the near-surface store for a while from the shrinking ponded area. Average detention and runoff both decrease sharply, with losses due to the runoff itself and the continuing infiltration.

4. In the final stage, all remaining water in the slope has infiltrated, and the near-surface stores gradually drain into the soil beneath.

5.

Figure 5 helps to further illustrate these stages of runoff and storage for storms of different total size $(8-480$ $\mathrm{mm}$ ) and intensity. In (a) storms all have a duration of two hours, and so widely varying intensities. In (b) the storms are at constant intensity of $60 \mathrm{~mm} \cdot$ hour $^{-1}$ and differing duration. In each case, infiltration initially 
absorbs almost all rainfall, and the small volume of runoff behaves as a power function of rainfall. For the fixed duration storms in (a) the final storage increases only very slightly with storm size and almost all additional rainfall is converted into runoff. With the storms of fixed intensity in (b), final storage rises significantly with increasing storm size., and only $82 \%$ of additional rainfall contributes to runoff. These differences are primarily due to the different durations of infiltration during rainfall and post-rainfall saturation. In Figure 6 , slope length has been added as an additional variable. The effect of increasing slope length is seen in an increase in the total available storage depth for large storms, and in the exponent of runoff for small storms.

The relationships seen here may be described as showing two asymptotic behaviours. For small storms infiltration approaches $100 \%$ of rainfall. For large storms, total infiltrated storage approaches an upper limit that increases primarily with storm duration, but also with slope length, which is linked to the duration of runoff after the storm ends. These two extreme behaviours are described by the relationships:

$S=R$ for $R<<\Theta(2)$

$\Sigma=\Theta$ for $R>>\Theta(3)$

Where $R=$ storm rainfall $(\mathrm{mm})$,

$S=$ Storm cumulative infiltration $(\mathrm{mm})$

and $\Theta=$ Storage threshold for cumulative infiltration (mm)

Empirically, the storage threshold may be expressed as

$\Theta=\beta+a T+\mathrm{c} \log _{2}\left(L / L_{0}\right)(4)$

Where $T$ is storm duration (hours),

and $L$ is slope length $(\mathrm{m})$

For the simulation the constants $a, b, c, L_{0}$ take the values

$a=10 \mathrm{~mm} \cdot \mathrm{hr}^{-1} ; b=10 \mathrm{~mm} ; \mathrm{c}=2 \mathrm{~mm} ; L_{0}=2.5 \mathrm{~m}$.

Repeated runs suggest that the constant $\left[b-c \log _{2}\left(\mathrm{~L}_{0}\right)\right]$ reflects the initially declining infiltration rate $[B$ in equation (1)]; the constant $a$ reflects the long-term final infiltration rate [A in equation (1)]. The constant $c$ reflects the duration of runoff after the end of rainfall, perhaps also reflecting long term infiltration rate.

Combining the asymptotic expression of equation (2) and (3), It is proposed to use the Michaelis-Mentem (Michaelis and Menten, 1913)/ Budyko (Budyko and Gerasimov, 1961) family of expressions, which take the form

$\frac{1}{S^{m}}=\frac{1}{R^{m}}+\frac{1}{\Theta^{m}}(5)$

$r=R-S(6)$

where $\mathrm{r}=$ storm total runoff $(\mathrm{mm})$, for some exponent $m>1$.

For runoff. this expression behaves asymptotically like

$r=\frac{R^{m+1}}{\mathrm{~m} \Theta^{m}}$ for $\mathrm{R}<<\Theta(7)$

$r=R-\Theta+\frac{\Theta^{m+1}}{\mathrm{~m} R^{m}}$ for $\mathrm{R}>>\Theta(8)$

and, at the cross-over point $(\mathrm{R}=\Theta)$,

$r=R \cdot 2^{-1 / m}$ for $\mathrm{R}=\Theta(9)$

These expression [equations (4)- (6)] provide an adequate description of the runoff response across the range of storms. There is a power law response for small storms, with the exponent $m=3-5$, and the runoff coefficient $(r / \mathrm{R})$ approaches $100 \%$ for the largest storms. Figure 7 compares values of (a) total storm storage and (b) total storm runoff obtained from the full simulation and from the regression equations (4) 
to (6) above. It can be seen that there is a satisfactory level of agreement in runoff over almost 6 orders of magnitude. Figure 7(c) compares the full model storage with the SCS method for Curve Numbers of 80 and 90, showing much greater divergences from the simulated storage. Substantial improvements in forecast runoff are also evident, particularly for smaller storms, although, to provide a useful forecast of storm runoff, the effect for large storms is seen as the more important. These expressions in equations (4) to (6) are considered to provide an enhanced replacement for the SCS curve number method.

The expression is relatively insensitive to the topography of the sloping surface. If similar storms are applied to the roughened surface of figure 1 and to a more strongly valleyed surface, estimated runoff values lie within the confidence bands, perhaps because runoff generation is a near-linear process. However, the different surfaces have a profound influence on sediment transport. If, as a first approximation, sediment transport is estimated as proportional to discharge squared multiplied by gradient the pattern of sediment transport strongly reflects the structure of ridges and valleys and is then generally dominated by the differences in area drained.

\section{Comparison with erosion plot data. The Sierra de Enguera Soil Erosion Experimental Station}

The model described above is compared with data for runoff from the site of El Teularet in the Sierra de Enguera, SSE of Valencia, Spain (Cerda et al., 2017; 2018). The Sierra de Enguera range within the Massís del Caroig in Eastern Spain (750 m.a.s.l., $38^{\circ} 55^{\prime}$ N, 00deg 50' W) was selected to establish the Sierra de Enguera Soil Erosion and Degradation Research Station (Figure 8). This is a rainfed and rangeland use region in the Eastern part of the Iberian Peninsula. The climate is typical Mediterranean with a mean annual temperature of $12.7 \operatorname{deg} \mathrm{C}$ as registered in the nearby meteorological station of Las Arenas Enguera ( $5 \mathrm{~km}$ from the study area). Mean annual rainfall is $540 \mathrm{~mm}$ and the soil texture is Clay loam and the soil is a Typic Xerorthent (Soil Survey Staff, 2014). The use of herbicides (glyphosate) was applied following the strategy of the farmers of the Sierra de Enguera. They applied herbicides when weeds were present with the objective to maintain the soil bare.

A set of five plots under different agriculture and forest managements were established between 2002 and 2003, and the first measurements took place in January 2004. The data used in this investigation were collected from 2004 to 2014 from plots treated with herbicide to suppress vegetation growth. Plots were bounded with aluminium sheets, $1 \mathrm{~mm}$ thick and $50 \mathrm{~mm}$ high, to achieve plots of different sizes $(1 \mathrm{x} 1 ; 1 \times 2$; $1 \times 4 ; 2 \times 8$ and $3 \times 16 \mathrm{~m}^{2}$ ) (Figure 8 ). Plots having different areas were obtained varying both plot lengths and widths and were established in an area having aq gradient of $5 \%$. Runoff $(\mathrm{mm})$, sediment concentration $\left(\mathrm{g} \mathrm{L}^{-1}\right)$ and soil loss $\left(\mathrm{g} \mathrm{m}^{-2}\right)$ were measured after each rainfall event. More than 6 hours without rainfall was used as the threshold to distinguish rainfall events. Runoff was collected from each plot by a $0.15 \mathrm{~m}$ wide and $0.15 \mathrm{~m}$ deep gutter. The collected runoff was conveyed, by a $0.4 \mathrm{~m}$ diameter pipe, into containers with storage capacities of $125,250,375,600$ and $1000 \mathrm{~L}$ for the $1,2,4,16$ and $48 \mathrm{~m}^{2}$ plots, respectively. Runoff volume was recorded after each major rainfall event.

The measurements of daily rainfall and runoff provided over 300 runoff measurements from 450 rain days. When it was not possible to measure runoff after every rainfall event, events between successive runoff measurements have been combined into a single 'effective rainfall'. Preliminary correlation showed that, for smaller events, runoff was proportional to the third power of rainfall. Effective rainfall over successive events was therefore calculated as $\left[\Sigma\left(\mathrm{r}^{3)}\right]^{(1 / 3)}\right.$, giving appropriately greater weight to the largest rainfall in the sequence. With this consolidation, measurable runoff was compared with the effective rainfall for 220 events.

Following equations (5) and (6) proposed above, the plot runoff and storage were estimated for all events and for the fourplot lengths $(1,2,4,8$ and $16 \mathrm{~m})$. With these data, it was found that the best fit between observed and estimated runoff was obtained for $=2$. A value for the storage threshold, $\Theta$ was then fitted for each of the plot lengths. With these values, Figure 9(a) shows the level of agreement between observed and estimated runoff for the 220 events and four plot lengths. $90 \%$ of the data points lie within the lines drawn around the 1:1 line. Figure 9 (b) shows the non-linear relationship found between the storage threshold, $\Theta$ 
and plot length. With no data on storm duration, it is difficult to compare directly with equation (1) above, though both show a diminishing increase in threshold with increasing plot length.

Values for the storm threshold have been selected to optimise estimates of runoff, and Figure 9(c) shows their impact on estimates of storage. Here the solid curves indicate the estimated storage [from equation (5)]. The plotted points are binned values, each the average for ten sequential values of ranked storm rainfall. The upper grey line is the 1:1 line, which has been seen to be the asymptotic state for small rainfalls [equation (2) above]. These curves should be visually compared with the forms of figures 6(b) and 6(d) above, suggesting that the field data lies closer to the constant duration $(m=2.8)$ than to the constant intensity storm model $(m=4.7)$. The consistent behaviour of the proposed storm runoff model provides some confidence in proposing equations (5) and (6) as a viable alternative to the widely used runoff model encapsulated in the SCS curve number approach.

\section{Discussion}

Figures 10 and 11 illustrate the implications of the model when extrapolated to longer slopes and more extreme rainfalls. Using the same parameter as in the field data, runoff coefficients are estimated as a function of storm rainfall for slopes of 5 to $50 \mathrm{~m}$ in figure 12, where they are compared with SCS curve number relationships. Over the storm sizes seen in the field data, the greatest relative divergences between the two approaches are found for the large number of storms of less than $30 \mathrm{~mm}$ and with less than $10 \%$ runoff, for which the SCS method consistently underpredicts the small volumes of runoff.

The importance of the proposed alternative runoff estimate is not, however, seen to lie in the quality of fit to individual data sets, all of which show wide variations that can be contained within either form of expression. What seems much more important and useful is that the proposed expression explicitly includes scaling for both rainfall intensity and slope length, providing a model with much greater possibilities for transference across scales and between sites and climates. Experimentation within the model environment also shows that the parameters in equation (4) also responds rationally to changes in infiltration parameters and their spatial variability, to gradient and to micro-topography expressed through the potential for locally divergent flow.

The potential to apply a model at different spatial scales within a catchment is of value, not only in support of field experiments but also to distribute runoff and sediment transport within a field area or within a landscape evolution model.

\section{Acknowledgements}

This research was funded by the European Union Seventh Framework Programme (FP7/2007-2013) under $\backslash \backslash$. Artemi Cerdà thanks the Co-operative Research programme from the OECD (Biological Resource Management for Sustainable Agricultural Systems) for its support with the 2016 CRP fellowship (OCDE TAD/CRP JA00088807). We thank Nathalie Elisseou Léglise for her kind management of our financial support. The collaboration of students from the Degree of Geography and Environmental Sciences was fruitful and enjoyable. The music of Hilari Alonso (A prop) was an inspiration during the writing of this paper at the COVID19 time.

\section{Data availability statement}

The runoff plot data used in the is study are available from the authors on reasonable request.

\section{References cited}

Bagarello, V., V. Ferro, S. Keesstra, J. R. Comino, M. Pulido and A. Cerda (2018). "Testing simple scaling in soil erosion processes at plot scale." Catena 167 : 171-180.

Bartlett, M. S., A. J. Parolari, J. J. McDonnell and A. Porporato (2016). "Framework for event-based semidistributed modeling that unifies the SCS-CN method, VIC, PDM, and TOPMODEL." Water Resources Research 52 (9): 7036-7052. 
Budyko, M. I. and I. P. Gerasimov (1961). The heat and water balance of the earth's surface, the general theory of physical geography and the problem of the transformation of nature. Soviet Geography Review and Translation 2 (2): 3-12.

Cammeraat, L. H. (2002). "A review of two strongly contrasting geomorphological systems within the context of scale." Earth Surface Processes and Landforms 27 (11): 1201-1222.

Cerdà, A., Rodrigo-Comino, J., Giménez-Morera, A., \& Keesstra, S. D. (2017). An economic, perception and biophysical approach to the use of oat straw as mulch in Mediterranean rainfed agriculture land. Ecological Engineering, 108, 162-171.

Cerdà, A., Rodrigo-Comino, J., Novara, A., Brevik, E. C., Vaezi, A. R., Pulido, M., .. \& Keesstra, S. D. (2018). Long-term impact of rainfed agricultural land abandonment on soil erosion in the Western Mediterranean basin. Progress in Physical Geography: Earth and Environment, 42(2), 202-219.

Dunne, T. and R. D. Black (1970). "Partial area contributions to storm runoff in a small New England watershed." Water Resources Research 6 : 1296-1311.

Gao, J. H., J. Holden and M. Kirkby (2015). "A distributed TOPMODEL for modelling impacts of land-cover change on river flow in upland peatland catchments." Hydrological Processes 29 (13): 2867-2879.

Green, W. H. and G. A. Ampt (1911). "Studies on soil physics Part I - The flow of air and water through soils." Journal of Agricultural Science 4 : 1-24.

Horton, R. E. (1931). "The role of infiltration in the hydraulic cycle." Transactions of the American Geophysical Union 12 : 13.

King, K. W., J. G. Arnold and R. L. Bingner (1999). "Comparison of Green-Ampt and curve number methods on Goodwin Creek Watershed using SWAT." Trancactions, American Society of Agricultural Engineers42 (4): 919-925.

Kirkby, M. J. (2014). "Do not only connect: a model of infiltration-excess overland flow based on simulation." Earth Surface Processes and Landforms 39 (7): 952-963.

Luk, S.-H. and C. Morgan (1981). "Spatial variations of rainwash and runoff within apparently homogeneous areas." Catena 8 (1): 383-402.

McDonnell, J. J. (2003). "Where does water go when it rains? Moving beyond the variable source area concept of rainfall-runoff response." Hydrological Processes 17 : 1869-1875.

McDonnell, J. J. (2013). "Are all runoff processes the same?" Hydrological Processes 27 : 4103-4111.

Michaelis, L. and M. L. Menten (1913). "The kenetics of the inversion effect." Biochemische Zeitschrift 49 : 333-369.

Wendt, R. C., E. E. Alberts and A. T. Hjelmfelt (1986). Variability of runoff and soil loss from fallow experimental plot. Soil Science Society of America Journal 50 (3): 730-736.

Williams, J. R., N. Kannan, X. Wang, C. Santhi and J. G. Arnold (2012). Evolution of the SCS Runoff Curve Number Method and Its Application to Continuous Runoff Simulation. Journal of Hydrologic Engineering17 (11): 1221-1229.

Williams, J. R. and W. V. Laseur (1976). Water yield model using SCS curves numbers. Journal of the Hydraulics Division-Asce102 (9): 1241-1253.

Zhang, D. J., Q. Y. Lin, X. W. Chen and T. Chai (2019). "Improved Curve Number Estimation in SWAT by Reflecting the Effect of Rainfall Intensity on Runoff Generation." Water 11 (1): 17.

Figure captions 
Figure 1: Conceptual regimes of lateral flow in the soil, defined by the depth below which rainfall or percolation intensity exceeds vertical hydraulic conductivity. Conditions are expected to change over time between and during storms, and to exhibit spatial variability.

Figure 2:

(a)Topography for example run.

'Smoothish' surface: $320 \times 320 \mathrm{~m}(128 \times 128$ cells $)$ area. $2 \mathrm{~m}$ contours. 5\% gradient

Divide at top: rolling lateral margins.

(b) Total storm discharge for example run on surface of (a). Total storm discharge (mm x cells) from a 120 $\mathrm{mm}$ storm at $30 \mathrm{~mm} /$ hour

Figure 3 .

(a)Total storm discharge as a function of drainage area for 3 lateral transects $(\mathrm{x}=20,64,118)$ across the area.

$120 \mathrm{~mm}$ storm at $30 \mathrm{~mm} / \mathrm{hr}$. Discharge increases less than linearly, so that runoff is declining downslope $\left(\mathrm{r}^{\sim}\right.$ $\left.\mathrm{A}^{-.4}\right)$.

(b) Total storm runoff as a function of drainage area for 3 lateral transects across the area. $30 \mathrm{~mm}$ storm at $60 \mathrm{~mm} / \mathrm{hr}$., with $4 \mathrm{x}$ higher infiltration rates. Note the divergence of individual transect trends.

Figure 4: Modelled evolution over time of spatially averaged surface detention, runoff, near-surface and total soil storage during and after 2 hour storms of uniform intensity.

$30 \mathrm{~mm}$ storm at $15 \mathrm{~mm} \cdot \mathrm{hr}^{-1}$

$120 \mathrm{~mm}$ storm at $60 \mathrm{~mm} \cdot \mathrm{hr}^{-1}$

Figure 5: Total storm slope base runoff and total storage for uniform storms of different total rainfall.

Note log scales for rainfall \& runoff. Arithmetic scale for storage.

Regressions apply to upper and lower portions of the curves separately.

Storms of 2-hour total duration (varying intensity)

Storms at $60 \mathrm{~mm} / \mathrm{hr}$ (varying duration)

For small storms, almost all rain infiltrates, so that storage =rainfall, and total runoff is small, generated by low infiltration patches close to the base of the slope. This behaves as a power law of storm rainfall (with exponent 2-5).

For large storms, ultimate storage depends on duration, scaled to steady long-term infiltration rate. Total runoff is controlled by the limiting storage, which depends on total storm (and runoff) duration.

Figure 6. The effect of slope length on the dependence of storm runoff and storm total storage on storm rainfall

(a) \& (b): For storms of 2-hour duration

(c) \& (d): for storms at $60 \mathrm{~mm} / \mathrm{hr}$

In each case, curves show the relationship for slopes of length 8, 16, 32 and 128 cells (20-320 m). For low rainfalls, storage lies close to the 1:1 line, at which all rainfall infiltrates.

Figure 7. Comparison between Total storm (a) Storage and (b) Runoff estimated from full model simulation in $128 \times 128$ cell grid, and regression model of equations (4) to (6) with the following parameter values: $a=$ $10 \mathrm{~mm} \cdot \mathrm{hr}^{-1} ; \mathrm{b}=10 \mathrm{~mm} ; \mathrm{c}=2 \mathrm{~mm} ; \mathrm{L}_{0}=2.5 \mathrm{~m} ; \mathrm{m}=4$ 
In graph legends, $\mathrm{x}=$ length in number of $2.5 \mathrm{~m}$ cells

Input values for slope length, $L=20-320 \mathrm{~m}$,

Storm rainfall $R=8-480 \mathrm{~mm}$, Storm Duration, $T=8 \mathrm{~min}-8 \mathrm{hr}$.

(c) Full model storage vs. SCS model for $\mathrm{CN}=80 \& 90$

Figure 8: View of the study plot at the Sierra de Enguera experimental station. Bare plots of width $\mathrm{x}$ length $1 \times 1,1 \times 2,1 \times 4,2 \times 8,4 \times 16 \mathrm{~m}$. Runoff collectors in the foreground. Inset location map of SE Spain.

Figure 9: Sierra de Enguera runoff plots: Regression estimate compared with measured runoff data.

Data for 220 events with measured runoff, 2005-2014.

Maximum event $=230 \mathrm{~mm}$ rainfall with $115 \mathrm{~mm}$ runoff.

Estimated storage, $\mathrm{S}=\Theta /\left[1+(\Theta / R)^{2}\right]^{0.5}$

Estimated runoff, $\mathrm{r}=\mathrm{R}-\mathrm{S}$

Where $\mathrm{R}=$ storm rainfall, $\mathrm{S}=$ storm storage, $\Theta=$ storage threshold.

Lines bracket $90 \%$ of the data points around the 1:1 line

(b) Storage threshold, $\Theta$ as a function of plot length, L.

$\Theta=26.5 \mathrm{~L}^{0.57}$

(c) Event storage, $\mathrm{S}$ as a function of $\mathrm{R} \& \Theta$. Data points are binned values, each the average for 10 events in rank order.

Figure 10: Response of runoff coefficient to storm size, storm intensity and slope length, following equation (5). Note non-zero responses to small storms. Parameter values as for Sierra de Enguera site. Dotted curves are for SCS curve number method for comparison.

Figure 11: Extrapolated response of runoff coefficient to slope length for a range of storm rainfalls $(R$ )following equation (5), with parameter values as for Sierra de Enguera site. Shorter slopes imply higher drainage densities. 
figures/CN-Fig1/CN-Fig1-eps-converted-to.pdf 
figures/CN-Fig2/CN-Fig2-eps-converted-to.pdf 
figures/CN-Fig3/CN-Fig3-eps-converted-to.pdf 
figures/CN-Fig4/CN-Fig4-eps-converted-to.pdf 
figures/CN-Fig5/CN-Fig5-eps-converted-to.pdf 
figures/CN-Fig6/CN-Fig6-eps-converted-to.pdf 
figures/CN-Fig7/CN-Fig7-eps-converted-to.pdf 
figures/fig8/fig8-eps-converted-to.pdf 
figures/CN-Fig9/CN-Fig9-eps-converted-to.pdf 
figures/fig10/fig10-eps-converted-to.pdf 
figures/fig11/fig11-eps-converted-to.pdf 